\title{
High dose vitamin D supplementation does not affect biochemical bone markers in multiple sclerosis - a randomized controlled trial
}

Trygve Holmøy ${ }^{1,2^{*}}$ (D), Jonas Christoffer Lindstrøm²,3, Erik Fink Eriksen ${ }^{2,4}$, Linn Hofsøy Steffensen ${ }^{5,6}$ and Margitta T. Kampman ${ }^{5}$

\begin{abstract}
Background: People with multiple sclerosis have high risk of osteoporosis and fractures. A poor vitamin D status is a risk factor for MS, and vitamin D supplementation has been recommended both to prevent MS progression and to maintain bone health.

Methods: We assessed the effect of 20,000 IU vitamin $D_{3}$ weekly compared to placebo on biochemical markers of bone metabolism in 68 persons with relapsing remitting multiple sclerosis.

Results: Serum levels of 25-hydroxyvitamin D more than doubled in the vitamin D group, and parathyroid hormone decreased in the vitamin D group compared to the placebo group at week 48 and week 96 . There was however no effect on bone formation as measured by procollagen type I $\mathrm{N}$ propeptide (PINP), or on bone resorption as measured by C-terminal cross-linking telopeptide of type I collagen (CTX1). Neither PINP nor CTX1 predicted bone loss from baseline to week 96.
\end{abstract}

Conclusions: These findings corroborate the previously reported lack of effect of weekly high dose vitamin D supplementation on bone mass density in the same patients, and suggest that such vitamin D supplementation does not prevent bone loss in persons with MS who are not vitamin D deficient.

Trial registration: The trial was registered at ClinicalTrials.gov on April 4 2008, registration number NCT00785473.

Keywords: Multiple sclerosis, vitamin D, osteoporosis, randomized controlled trial

\section{Background}

Low levels of vitamin D are associated with increased future risk of developing multiple sclerosis and with increased disease activity [1-3]. Vitamin D is also essential for bone health. Several studies have shown that people with multiple sclerosis (MS) are at increased risk of developing osteoporosis $[4,5]$. Physical disability is likely the main driver of accelerated bone loss in MS, but also disease duration and lifetime steroid dose are associated with low bone mineral density (BMD) $[4,6]$. Low BMD is however prevalent also in ambulatory persons with

\footnotetext{
* Correspondence: Trygve.holmoy@medisin.uio.no

${ }^{1}$ Department of Neurology, Akershus University Hospital, Lørenskog, Norway

${ }^{2}$ Institute of Clinical Medicine, University of Oslo, Oslo, Norway

Full list of author information is available at the end of the article
}

MS even shortly after clinical onset [6, 7], suggesting that shared etiological factors such as low vitamin D may operate in both MS and osteoporosis.

The combination of osteoporosis and high risk of falling may add to the burden of disease through increased risk of fractures. In line with this, large population based studies have shown that persons with MS have a marked increase of fractures compared to the general population [8-12]. Data from the Danish MS Registry and The National Hospital Discharge Registry showed that the risk of fractures of tibia, hip and femur in persons with MS was three to six times higher than in the general population [10].

Although the role of vitamin D supplementation on disease activity in MS is unclear [13], several authors have suggested that vitamin $\mathrm{D}$ should be monitored to 
prevent osteoporosis and fractures [5, 14-16]. The optimal intake of vitamin D and serum level of 25-hydroxyvitamin $\mathrm{D}$ is however controversial. Whereas the National Institute of Medicine considers a serum level of 25-hydroxyvitamin $(25(\mathrm{OH}) \mathrm{D})$ at $50 \mathrm{nmol} / \mathrm{L}$ and a daily intake of $600 \mathrm{IU}$ vitamin D adequate for the general population [17], others argue that the serum level needed for both optimal bone health and for the potentially beneficial non-calcemic effects is at least $75 \mathrm{nmol} / \mathrm{L}$ [18-20]. There is, however limited evidence on the effect of vitamin D supplementation on bone heath in MS.

We have previously reported a randomized controlled trial (RCT) of weekly supplementation with 20,000 IU vitamin $\mathrm{D}_{3}$ compared to placebo in fully ambulatory (expanded disability status scale $\leq 4.5$ ) persons with relapsing remitting MS living above the Arctic Circle [21]. This dose has proven safe in several RTCs in the same area [22]. Even though people with MS may need more vitamin D than others to reach the same 25hydroxyvitamin D $(25(\mathrm{OH}) \mathrm{D})$ serum concentration, [23], we expected that this dose would bring the vast majority of patients to $25(\mathrm{OH}) \mathrm{D}$ levels considered optimal for bone health and also within the range associated with decreased disease activity. Although bone mineral density (BMD) decreased significantly in the placebo group and not in the vitamin $\mathrm{D}$ treated group, the primary outcome (difference in percentage change in BMD between groups) was negative [21].

The markers of bone formation procollagen type I $\mathrm{N}$ propeptide (PINP) and bone resorption C-terminal cross-linking telopeptide of type I collagen (CTX1) have been shown to predict fracture risk and to reflect the response to osteoporosis treatment [24]. These markers are recommended as reference markers in observational and treatment studies in osteoporosis by the International Osteoporosis Foundation and the International Federation of Clinical Chemistry and Laboratory Medicine [25], and could be more sensitive for treatment effects than BMD. The aim of the current study was to examine if CTX and PINP predict bone loss, and if vitamin $\mathrm{D}_{3}$ supplementation affect these markers of bone formation and turnover in persons with MS.

\section{Methods}

The design of the RCT have been reported previously [21, 26]. Briefly, 71 RRMS patients from Troms and Finnmark (the northernmost counties in Norway), aged $18-50$ years and with Kurtzke's Expanded Disability Status Scale (EDSS) score $\leqslant 4.5$ were included in the original study [21]. The exclusion criteria comprised a history of conditions or diseases affecting bone, pregnancy or lactation the past 6 months, use of bone-active medications other than intravenous methylprednisolone for treatment of MS relapses, a history of nephrolithiasis during the previous 5 years, or menopause.

The participants were randomized to receive either once-weekly oral 20,000 IU vitamin $\mathrm{D}_{3}$ (Dekristol ${ }^{\mathrm{Tw}}$; SWISS CAPS AG, Kirchberg, Switzerland) or placebo. All participants also received $500 \mathrm{mg}$ calcium daily (calcium carbonate, Weifa AS, Oslo, Norway). Participants who had gastrointestinal side effects attributed to Weifa calcium switched to Calcium Sandoz ${ }^{\text {Tix }}$ effervescent tablets (calcium lactate-gluconate and calcium carbonate, Sandoz A/S, Odense, Denmark), or discontinued the calcium supplement if their estimated dietary calcium intake as measured by a validated food frequency questionnaire exceeded $800 \mathrm{mg} /$ day [27]. By capsule count, all subjects were $\geq 80 \%$ (mean $98 \%$, range $80-100 \%$ ) adherent to the study medication [21].

Measurement of BMD at the hip (mean of left and right), the spine (anterior-posterior spine L1-L4), and the non-dominant ultra-distal radius by DXA (dual X-ray absorptiometry) was performed by trained technicians at the University Hospital of North-Norway, using a Lunar Prodigy advanced densitometer (Lunar Radiation Corp., Madison, WI, USA.). The long-term precision was 0.26$0.28 \%$, obtained by daily calibration of the densitometer. One fourth of the patients had low BMD (z-scores blow -2) at baseline [6].

Serum samples were collected at baseline (January or February for all participants) and at week 48 and 96 (randomly to intake of vitamin D supplementation), and frozen at $-70{ }^{\circ} \mathrm{C}$ until batch analyses. 25(OH)D was measured by spectroscopy detecting total concentrations of both $25(\mathrm{OH}) \mathrm{D}_{2}$ and $25(\mathrm{OH}) \mathrm{D}_{3}$ at the Hormone laboratory at Haukeland University Hospital. The coefficient of variat4ion $(\mathrm{CV})$ was $5.3 \%$ at $20 \mathrm{nmol} / \mathrm{L}$ and $4.0 \%$ at 239 $\mathrm{nmol} / \mathrm{L} 25(\mathrm{OH}) \mathrm{D}$. PINP and CTX1 were measured by electrochemiluminiscence at the Hormone laboratory at Oslo University Hospital. The CVs were 11\% for PINP and $12 \%$ for CTX1, and the detection limits were 5-1200 $\mu \mathrm{g} / \mathrm{l}$ and $0,07-6,00 \mu \mathrm{g} / \mathrm{l}$ respectively.

The associations between bone markers and BMD at baseline, and whether the concentrations of PINP and CTX1 at baseline predicted BMD change from baseline to week 96, were analyzed with linear regression. The longitudinal changes in CTX1, PINP and PTH were modelled with two separate linear mixed models. The models included time of measurement, treatment arm, time-treatment interaction, and a random intercept for each participant. The markers were log-transformed, making the estimated differences interpretable as percentages. The models formed the basis for all inferences on the relationship between vitamin $\mathrm{D}$ and the markers. To investigate whether disease modifying drugs could influence the results, we also used a model which included the drug treatment status at each sample time. 
Table 1 Baseline characteristics

\begin{tabular}{llll}
\hline & & Vitamin D group $(N=35)$ & Placebo group $(N=33)$ \\
\hline Females & $\mathrm{N}(\%)$ & $24(69)$ & $24(73)$ \\
Age (years) & Mean (range) & $40(21-50)$ & $41(26-50)$ \\
Body mass index & Mean (range) & $25.9(21.0-40.7)$ & $26.4(18.4-39.9)$ \\
Ongoing smoking & $\mathrm{N}(\%)$ & $15(43)$ & $14(42)$ \\
EDSS & Median (range) & $2.5(0-4.5)$ & $2.0(0-4.5)$ \\
Annualised relapse rate & Mean (range) & $0.11(0-0.54)$ & $0.15(0-1.10)$ \\
Immunomodulatory treatment & $\mathrm{N}(\%)$ & $17(49)^{\mathrm{a}}$ & $17(52)^{\mathrm{b}}$ \\
Serum 25(OH)D $(\mathrm{nmol} / \mathrm{L})$ & Mean (SD) & $55.6(29.0)$ & $57.3(21.8)$ \\
Hip BMD $\left(\mathrm{mg} / \mathrm{cm}^{2}\right)$ & Mean (SD) & $1018.8(98.8)$ & $968.9(119.9)$ \\
Spine BMD $\left(\mathrm{mg} / \mathrm{cm}^{2}\right)$ & Mean (SD) & $1205.2(117.7)$ & $1165.7(135.6)$ \\
Distal radius BMD $\left(\mathrm{mg} / \mathrm{cm}^{2}\right)$ & Mean (SD) & $484.8(67.1)$ & $472.8(80.6)$ \\
\hline
\end{tabular}

a 16 patients on IFN- $\beta$ and one on glatiramer acetate

${ }^{b} 15$ patients on IFN- $\beta$, one on glatiramer acetate and one on natalizumab

\section{Results}

Serum samples for measurement of bone markers were available from 68 participants who completed the study. Baseline characteristics of the study population are shown in Table 1. As reported previously [28] there were no group differences in age, body mass index (BMI), smoking, use of disease modifying drugs, disability as measured by EDSS, calcium intake or relapse rate the previous year. The serum concentration of $25(\mathrm{OH}) \mathrm{D}$ increased to $123.2 \pm 34.2 \mathrm{nmol} / \mathrm{L}$ at week 96 in the vitamin $\mathrm{D}$ group, and to $61.8 \pm 25.2 \mathrm{nmol} / \mathrm{L}$ in the placebo group. Ionized calcium was similar and unchanged at baseline and week 96 in both groups $(1.2 \pm 0.0 \mathrm{nmol} / \mathrm{L})$.

The concentrations of CTX1, PINP and PTH did not differ significantly between the groups at baseline (Table 2). The concentrations of CTX1 and PINP remained similar between treatment groups throughout the study group, whereas PTH was lower in the vitamin D group at both week 48 and at week 96 .

The associations between the bone markers and BMD are presented in Table 3. There was a weak negative association between CTX1 and PINP and hip BMD at baseline, and between CTX1 and spine BMD at baseline $(p<0.05)$. The baseline marker concentrations did not predict change in BMD from baseline to week 48 or week 96.
The effect of vitamin D supplementation was finally analyzed using a linear mixed model for each bone marker with random patient-wise intercepts. There was no significant difference between treatment groups in the change of CTX1, PINP or PTH from baseline to week 48 or from baseline to week 96 (Table 4). These results did not change substantially when immune modulatory treatment was included in the model (results not shown). In total 14 patients received methylprednisolone for MS attack. Of these two in the placebo and two in the vitamin D groups were treated during the last 6 months prior to the first blood sampling, and three in the vitamin $\mathrm{D}$ group and one in the placebo group during the last 6 months prior to the last blood sampling. Excluding the 14 patients treated with methylprednisolone did not alter the results (data nor shown).

\section{Discussion}

To our knowledge the effect on vitamin D supplementation on markers of bone formation and resorption in persons with MS has not been reported previously. We found that increasing mean 25(OH)D levels from 56 to 123 $\mathrm{nmol} / \mathrm{L}$ with weekly high dose vitamin $\mathrm{D}$ supplementation did not influence biochemical markers of bone formation or turnover in persons with MS receiving calcium supplementation. This concurs with the previously negative

Table 2 Bone markers and PTH throughot the study period

\begin{tabular}{|c|c|c|c|c|c|c|c|c|c|}
\hline & \multicolumn{3}{|l|}{ CTX1 $(\mu \mathrm{g} / \mathrm{l})$} & \multicolumn{3}{|l|}{ PINP ( $\mu \mathrm{g} / \mathrm{l})$} & \multicolumn{3}{|c|}{$\mathrm{PTH} \mathrm{pmol} / \mathrm{L}$} \\
\hline & Placebo & Vitamin D & $p$-value & Placebo & Vitamin D & $p$-value* & Placebo & Vitamin D & $p$-value* \\
\hline Baseline. mean (SD) & $0.20(0.10)$ & $0.22(0.11)$ & 0.59 & $43.10(15.1)$ & $40.32(10.0)$ & 0.57 & $4.75(1.08)$ & $4.68(1.29)$ & 0.66 \\
\hline Week 48. mean (SD) & $0.22(0.16)$ & $0.21(0.11)$ & 0.79 & $43.36(17.2)$ & $38.56(10.6)$ & 0.43 & $3.68(1.04)$ & $3.13(0.96)$ & 0.017 \\
\hline Week 96. mean (SD) & $0.23(0.17)$ & $0.23(0.12)$ & 0.98 & $42.54(15.0)$ & $43.52(10.6)$ & 0.22 & $3.96(1.27)$ & $3.39(1.00)$ & 0.046 \\
\hline
\end{tabular}

*Obtained from linear mixed model 
Table 3 Association between bone markers at baseline and BMD (regression coefficients)

\begin{tabular}{lll}
\hline BMD & CTX1 & PINP \\
\hline Baseline hip & $-279.4^{*}$ & $-2.42^{*}$ \\
Baseline spine & $-385.0^{*}$ & -2.12 \\
Baseline distal radius & 91.3 & 1.05 \\
DELTA hip & -7.6 & 0.10 \\
DELTA spine & 61.5 & 0.40 \\
DELTA distal radius & -30.9 & 0.30 \\
\hline
\end{tabular}

${ }^{*} p<0.05$; DELTA indicated the difference in BMD from baseline to week 96

results on BMD in the same cohort [21], and also with data obtained in healthy persons [29]. Moreover, we here showed that neither CTX1 nor PINP at baseline predicted BMD loss the subsequent 96 weeks. This is in contrast with a previous study comprising 29 MS patients followed for $3.1 \pm 1.9$ years, reporting a decline in BMD in the hip but not in the lumbal spine correlated inversely with bone turnover markers [30]. Whereas the patients included in these studies were fairly comparable regarding disease duration, BMI and disability levels, all known to be important for bone health in MS, only $50 \%$ of our patients received immunomodulatory treatment compared to $100 \%$ in the previous study [30]. Immunomodulatory drugs, including interferon beta which was most commonly used by our patients, could affect bone loss [31]. The use of immunomodulatory treatment did however not influence the effect of vitamin D on bone markers, and was not associated with BMD at baseline in our patients [32]. Other possible explanations for this discrepancy include differences in sample sizes and duration of follow up.

The vitamin D measurements in this study were performed in January and February and should therefore represent the seasonal nadir fairly well [33]. At this time point 18 of 35 patients in the treatment group had 25(OH)D levels above $50 \mathrm{nmol} / \mathrm{L}$, which are considered adequate for maintenance of good bone health by the Institute of Medicine. Clear evidence of vitamin D deficiency $(25(\mathrm{OH}) \mathrm{D}$ below $25 \mathrm{nmol})$ were only recorded in nine patients in each treatment group. It is conceivable that people with vitamin deficiency have a better effect of vitamin D supplementation on bone health than people with adequate vitamin $\mathrm{D}$ status, and that the low proportion of patients with vitamin D deficiency contributed to the negative results.

RCTs of vitamin D supplementation have not shown a consistent effect on BMD or fracture risk in the general population [17]. This does not exclude that particular subgroups with increased risk of osteoporosis due to immobilization, inadequate nutrition, medication or disease may need vitamin $\mathrm{D}$ supplementation to maintain bone health [8]. Our study population had rather low disease activity and their ambulation was only moderately impaired. MS patients with more advanced disability are more prone to both accelerated bone loss and vitamin D deficiency D [34], and could benefit more from vitamin D supplementation than those included in this study.

There are several strengths and limitations of this study. The randomized design minimized the risk of selection bias, and rigorous follow-up throughout the study period ensured adherence to the study medication. The optimal 25(OH)D level for bone health is not known, but the dose used in this trial was well above $800 \mathrm{IU}$ per day which has been suggested to prevent fracture in metaanalysis [35], and brought $25(\mathrm{OH}) \mathrm{D}$ in most patients above $75-100 \mathrm{nmol} / \mathrm{L}$ which has been suggested by several experts to be adequate $[19,36]$. The main weakness of the study is the limited size, which was not sufficient to perform subgroup analyses or to detect minor yet relevant effects of vitamin D supplementation. Moreover, patients were allowed to continue use of vitamin D supplements, and more than $50 \%$ of the patients in the placebo group reported a vitamin D intake exceeding $7.5 \mu \mathrm{g} /$ day. This concurs with the generally favorable vitamin $\mathrm{D}$ status of our patients. It is conceivable that depriving the patients from their vitamin D supplements could have increased the chance for a positive result, but it would expose patients in the placebo group to the risks of vitamin D deficiency, and would be particularly problematic in a population living north of the Arctic Circle. Another potential weakness is the use of weekly dosing of vitamin D3. Although weekly dosing leads to a stable serum concentration of $25(\mathrm{OH}) \mathrm{D}$, which has a long half- life, the effect on other vitamin D metabolites is different. Notably, the serum concentration of native vitamin $\mathrm{D}$, which likely plays an important role as substrate for synthesis of active 1,25-dihydroxyvitamin $\mathrm{D}$ in several tissues, peaks after six to $8 \mathrm{~h}$ and thereafter falls rapidly [37]. It is therefore

Table 4 Effect of high dose vitamin D supplementation compared to placebo on bone markers

\begin{tabular}{lllllll}
\hline & Week 48 & & \multicolumn{2}{l}{ Week 96} & \\
\cline { 2 - 3 } & Change from baseline, percent difference $(95 \% \mathrm{Cl})$ & & $p$-value* & & Change from baseline, percent difference $(95 \% \mathrm{Cl})$ & $p$-value* \\
\hline PINP & $-5.10 \%(-17.77,7.56)$ & 0.43 & & $10.26 \%(-2.4822 .99)$ & 0.12 \\
CTX1 & $-6.68 \%(-33.62,20.25)$ & 0.63 & & $-3.60 \%(-30.67,23.48)$ & 0.80 \\
PTH & $-13.69 \%(-29.55,2.12)$ & 0.09 & $-10.9 \%(-26.81,5.03)$ & 0.17 \\
\hline
\end{tabular}

*Obtained from linear mixed model 
possible that daily supplementation is better than weekly supplementation of vitamin D.

\section{Conclusions}

Our results do not support that high dose weekly vitamin D supplementation is beneficial for bone health in ambulatory persons with MS, and suggest that weekly vitamin D supplementation alone is not sufficient to prevent bone loss in persons with MS who are not vitamin D deficient.

\section{Abbreviations}

25(OH)D: 25-hydroxyvitamion D; BMD: Bone mineral density; CTX1: C-terminal cross-linking telopeptide of type I collagen; CV: Coefficient of variation; MS: Multiple sclerosis; PINP: Procollagen type $1 \mathrm{~N}$-terminal propeptide; PTH: Parathyroid hormone

\section{Acknowledgements}

Not applicable.

\section{Funding}

The study was funded by The University of Oslo.

\section{Availability of data and materials}

The datasets used during the current study available from the corresponding author on reasonable request.

\section{Authors' contributions}

TH planned the study, collected data, and wrote the manuscript. JCV analyzed the data and revised the manuscript. EFE planned the study and revised the manuscript. LSH and MTK planned the study, collected data and revised the manuscript. All authors read and approved the final manuscript.

\section{Competing interests}

On behalf of all authors, the corresponding author states that there is no competing interest.

\section{Consent for publication}

Not applicable.

\section{Ethics approval and consent to participate}

The study was approved by the Regional Committee for Research Ethics Northern Norway approved the study protocol (REK NORD 98/2006), and participants gave written informed consent to participate and to publication.

\section{Publisher's Note}

Springer Nature remains neutral with regard to jurisdictional claims in published maps and institutional affiliations.

\section{Author details}

'Department of Neurology, Akershus University Hospital, Lørenskog, Norway. ${ }^{2}$ Institute of Clinical Medicine, University of Oslo, Oslo, Norway. ${ }^{3}$ Helse Øst Health Services and Research Centre, Akershus University Hospital, Lørenskog, Norway. 'Department of Endocrinology, Oslo University Hospital, Oslo, Norway. ${ }^{5}$ Department of Neurology, University Hospital of North Norway, Tromsø, Norway. ${ }^{6}$ Department of Clinical Medicine, University of Tromsø, Tromsø, Norway.

Received: 18 November 2016 Accepted: 29 March 2017 Published online: 04 April 2017

\section{References}

1. Munger KL, Levin LI, Hollis BW, Howard NS, Ascherio A. Serum 25hydroxyvitamin D levels and risk of multiple sclerosis. JAMA. 2006;296:2832-8.

2. Løken-Amsrud KI, Holmøy T, Bakke SJ, Beiske AG, Bjerve KS, Bjørnarå BT, et al. Vitamin D and disease activity in multiple sclerosis before and during interferon beta treatment. Neurology. 2012;79:267-73.
3. Simpson Jr S, Taylor B, Blizzard L, Ponsonby AL, Pittas F, Tremlett H, et al. Higher 25-hydroxyvitamin D is associated with lower relapse risk in multiple sclerosis. Ann Neurol. 2010;68:193-203.

4. Huang Z, Qi Y, Du S, Chen G, Yan W. Bone mineral density levels in adults with multiple sclerosis: A meta-analysis. Int J Neurosci. 2015;125:904-12.

5. Gupta S, Ahsan I, Mahfooz N, Abdelhamid N, Ramanathan M, WeinstockGuttman B. Osteoporosis and multiple sclerosis: risk factors, pathophysiology, and therapeutic interventions. CNS Drugs. 2014;28:731-42.

6. Steffensen LH, Mellgren SI, Kampman MT. Predictors and prevalence of low bone mineral density in fully ambulatory persons with multiple sclerosis. $J$ Neurol. 2010;257:410-8.

7. Moen SM, Celius EG, Sandvik L, Nordsletten L, Eriksen EF, Holmoy T. Low bone mass in newly diagnosed multiple sclerosis and clinically isolated syndrome. Neurology. 2011;77:151-7.

8. Silk LN, Greene DA, Baker MK, Jander CB. The effect of calcium and vitamin D supplementation on bone health of male Jockeys. J Sci Med Sport. 2016; doi:10.1016/j.jsams.2016.08.004.

9. Bazelier MT, van Staa TP, Uitdehaag BM, Cooper C, Leufkens HG, Vestergaard $\mathrm{P}$, et al. The risk of fracture in patients with multiple sclerosis: the UK general practice research database. J Bone Miner Res. 2011;26:2271-9.

10. Bazelier MT, de Vries F, Bentzen J, Vestergaard P, Leufkens HG, van Staa TP, et al. Incidence of fractures in patients with multiple sclerosis: the Danish National Health Registers. Mult Scler. 2012;18:622-7.

11. Bazelier MT, van Staa TP, Uitdehaag BM, Cooper C, Leufkens HG, Vestergaard $\mathrm{P}$, et al. Risk of fractures in patients with multiple sclerosis: a population-based cohort study. Neurology. 2012;78:1967-73.

12. Ramagopalan SV, Seminog O, Goldacre R, Goldacre MJ. Risk of fractures in patients with multiple sclerosis: record-linkage study. BMC Neurol. 2012;12:135. doi:10.1186/1471-2377-12-135

13. James E, Dobson R, Kuhle J, Baker D, Giovannoni G, Ramagopalan SV. The effect of vitamin D-related interventions on multiple sclerosis relapses: a meta-analysis. Mult Scler. 2013:19:1571-9.

14. Hearn AP, Silber E. Osteoporosis in multiple sclerosis. Mult Scler. 2010;16:1031-43.

15. Dobson R, Ramagopalan S, Giovannoni G. Bone health and multiple sclerosis. Mult Scler. 2012;18:1522-8.

16. Kampman MT, Eriksen EF, Holmoy T. Multiple sclerosis, a cause of secondary osteoporosis? What is the evidence and what are the clinical implications? Acta Neurol Scand Suppl. 2011:44-9.

17. RossCA TCL, Yaktine AL, Del Valle HB. Institute of Medicine. Daily reference values for calcium and vitamin D. Washington DC: The National Academic Press; 2011

18. Priemel M, von DC, Klatte TO, Kessler S, Schlie J, Meier S, et al. Bone mineralization defects and vitamin D deficiency: histomorphometric analysis of iliac crest bone biopsies and circulating 25-hydroxyvitamin D in 675 patients. J Bone Miner Res. 2010;25:305-12.

19. Vieth $R$. Why the minimum desirable serum 25-hydroxyvitamin $D$ level should be $75 \mathrm{nmol} / \mathrm{L}(30 \mathrm{ng} / \mathrm{ml})$. Best Pract Res Clin Endocrinol Metab. 2011;25:681-91.

20. Pludowski P, Holick MF, Grant WB, Konstantynowicz J, Mascarenhas MR, Haq A, et al. Vitamin D supplementation guidelines. J Steroid Biochem Mol Biol. 2017; doi:10.1016/j.jsbmb.2017.01.021.

21. Steffensen LH, Jorgensen L, Straume B, Mellgren SI, Kampman MT. Can vitamin $\mathrm{D}(3)$ supplementation prevent bone loss in persons with MS? A placebo-controlled trial. J Neurol. 2011;258:1624-31.

22. Jorde R, Grimnes G, Hutchinson MS, Kjaergaard M, Kamycheva E, Svartberg J. Supplementation with vitamin D does not increase serum testosterone levels in healthy males. Horm Metab Res. 2013:45:675-81.

23. Bhargava P, Steele SU, Waubant E, Revirajan NR, Marcus J, Dembele M, et al. Multiple sclerosis patients have a diminished serologic response to vitamin D supplementation compared to healthy controls. Mult Scler. 2016;22:753-60.

24. Johansson H, Oden A, Kanis JA, McCloskey EV, Morris HA, Cooper C, et al. A meta-analysis of reference markers of bone turnover for prediction of fracture. Calcif Tissue Int. 2014;94:560-7.

25. Vasikaran S, Eastell R, Bruyere O, Foldes AJ, Garnero P, Griesmacher A, et al. Markers of bone turnover for the prediction of fracture risk and monitoring of osteoporosis treatment: a need for international reference standards. Osteoporos Int. 2011;22:391-420.

26. Kampman MT, Steffensen LH, Mellgren SI, Jorgensen L. Effect of vitamin D3 supplementation on relapses, disease progression and measures of function in persons with multiple sclerosis: exploratory outcomes from a double-blind randomised controlled trial. Mult Scler. 2012;18:1144-51. 
27. Hjartaker A, Andersen LF, Lund E. Comparison of diet measures from a foodfrequency questionnaire with measures from repeated 24-hour dietary recalls. The Norwegian Women and Cancer Study. Public Health Nutr. 2007;10:1094-103.

28. Rosjo E, Lossius A, Abdelmagid N, Lindstrom JC, Kampman MT, Jorgensen L, et al. Effect of high-dose vitamin D3 supplementation on antibody responses against Epstein-Barr virus in relapsing-remitting multiple sclerosis. Mult Scler Mult Scler. 2017;23:395-402.

29. Aloia J, Bojadzievski T, Yusupov E, Shahzad G, Pollack S, Mikhail M, et al. The relative influence of calcium intake and vitamin $D$ status on serum parathyroid hormone and bone turnover biomarkers in a double-blind, placebo-controlled parallel group, longitudinal factorial design. J Clin Endocrinol Metab. 2010;95:3216-24.

30. McKenna MJ, Murray B, Lonergan R, Redmond JM. Immunomodulators for multiple sclerosis may ameliorate spinal bone loss. Ir J Med Sci. 2013;182:29-32.

31. Abraham AK, Ramanathan M, Weinstock-Guttman B, Mager DE. Mechanisms of interferon-beta effects on bone homeostasis. Biochem Pharmacol. 2009;77:175762.

32. Kampman MT, Steffensen LH. Comment on Shuhaibar et al: Favourable effect of immunomodulator therapy on bone mineral density in multiple sclerosis. Ir J Med Sci. 2009;178:235-6.

33. Saltyte Benth J, Myhr KM, Loken-Amsrud KI, Beiske AG, Bjerve KS, Hovdal H, et al. Modelling and prediction of 25-hydroxyvitamin D levels in Norwegian relapsingremitting multiple sclerosis patients. Neuroepidemiology. 2012;39:84-93.

34. Huang Z, Qi Y, Du S, Chen G, Yan W. BMl levels with MS Bone mineral density levels in adults with multiple sclerosis: a meta-analysis. Int J Neurosci. 2015:125:904-12

35. Bischoff-Ferrari HA, Willett WC, Orav EJ, Lips P, Meunier PJ, Lyons RA, et al. A pooled analysis of vitamin $D$ dose requirements for fracture prevention. $N$ Engl J Med. 2012;367:40-9.

36. Souberbielle JC, Body J, Lappe JM, Plebani M, Shoenfeld Y, Wang TJ, et al. Vitamin D and musculoskeletal health, cardiovascular disease, autoimmunity and cancer: Recommendations for clinical practice. Autoimmun Rev. 2010;9:709-15.

37. Hollis BW, Wagner CL. Clinical review: The role of the parent compound vitamin D with respect to metabolism and function: Why clinical dose intervals can affect clinical outcomes. J Clin Endocrinol Metab. 2013:98:4619-28.

\section{Submit your next manuscript to BioMed Central and we will help you at every step:}

- We accept pre-submission inquiries

- Our selector tool helps you to find the most relevant journal

- We provide round the clock customer support

- Convenient online submission

- Thorough peer review

- Inclusion in PubMed and all major indexing services

- Maximum visibility for your research

Submit your manuscript at www.biomedcentral.com/submit

) Biomed Central 